\title{
Variabilidade genética utilizando descritores morfológicos para acessos de capsicum spp. para fins ornamentais
}

\author{
Petterson Baptista da LUZ ${ }^{1}$, Alessandro Aparecido Brito dos SANTOS ${ }^{1}$, \\ Valdete Campos AMBROZIO ${ }^{1}$
}

${ }^{1}$ Universidade do Estado de Mato Grosso, Cáceres, MT, Brasil.

*E-mail: petterbaptista@yahoo.com.br

Recebido em fevereiro/2019; Aceito em agosto/2019.

\begin{abstract}
RESUMO: O mercado de pimentas para fins ornamentais é um setor recém explorado, mas com grande potencial de crescimento no ramo de floricultura e paisagismo. As pimenteiras que possuem folhagem variegada, porte baixo, frutos com coloração variada em seus diferentes estádios de maturação, contrastando com as folhagens, já são utilizadas como plantas ornamentais, cultivadas e comercializadas em vasos. O presente trabalho teve como objetivo avaliar a variabilidade genética visando o potencial ornamental de acessos de Capsicum spp. através de modelos biométricos. Foram utilizados 55 acessos de Capsicum spp, e a caracterização morfoagronômica dos acessos foi realizada avaliando diferentes partes da planta. O terceiro par de correlações canônicas, com correlação de 0,51 , associa plantas com área do dossel compacto-densa, com menor comprimento e largura de dossel e de pequeno porte, associado com folhagens estreitas e de pecíolo grande. Esta associação é vantajosa para ornamentação. Ficou evidenciada a presença de variabilidade genética na população, o que é bastante favorável ao melhoramento na medida em que a heterogeneidade genética possibilita a obtenção de ganhos por meio de seleção.
\end{abstract}

Palavras-chave: pimenta; modelos biométricos; correlações canônicas; análise de trilha.

\section{Genetic variability focused on ornamental potential of a Capsicum spp. accession}

\begin{abstract}
Pepper market for ornamental purposes is recently exploited; however, it has a great growth potential in floriculture and landscaping. Pepper with variegated foliage, small size, and varied fruit coloration at different ripening stages contrasting with leaves have already been used as ornamental plants cultivated and purchased as potted plants. This study aimed to evaluate genetic variability of Capsicum spp. focusing on its ornamental potential by means of biometric templates. Fifty-five Capsicum spp. accessions were used and a morpho-agronomic characterization of the accessions were performed by evaluating different plant parts. The third canonical correlations are 0.51 and it associates compact-dense, small, shorter length and width canopy plants with narrow foliage and large petiole, which is advantageous for ornamentation. Genetic variation was evidenced in the population being very favorable for plant breeding programs once genetic heterogeneity enables obtaining gains through selections.
\end{abstract}

Keywords: pepper; biometric templates; canonic correlations; trail analysis.

\section{INTRODUÇ̃̃O}

$\mathrm{O}$ cultivo de plantas ornamentais refere-se à produção de plantas que não são utilizadas para alimentação, sendo seu objetivo embelezar, decorar ou realçar o ambiente (OLIVEIRA et al., 2006). O desenvolvimento do agronegócio de plantas ornamentais está se expandindo a cada ano em todo o mundo (BOTELHO et al., 2015). O interesse por pimenteiras ornamentais aumentou e já é tendência no segmento floricultor (SILVA et al., 2015), entretanto, existem poucas variedades comerciais destinadas a esse propósito no Brasil, sendo, portanto, relevante conhecer o potencial ornamental de acessos de pimenteiras presentes em bancos de Germoplasma (NEITZKE et al., 2010; MELO et al., 2014).

A análise morfologia de divergência genética entre os acessos de pimenteiras permite identificar o potencial específico de cada acesso para ser usado em programas de melhoramento. A caracterização permite verificar a existência de acessos com potencial ornamental, sendo possível assim identificar o acesso de pimenteira de acordo com as características mais apreciadas para ornamentação (BABA et al., 2016).

Para a caracterização morfológica para potencial ornamental, podem-se usar diferentes métodos estatísticos. Dos quais, tem-se a Análise de Trilha e as Correlações Canónicas. De acordo Cruz et al. (2012), a escolha do método estatístico depende da precisão desejada pelo pesquisador, da facilidade da análise e da forma como os dados são obtidos.

De acordo com Cruz; Regazzi (1994), o sucesso da análise de trilha reside basicamente na formulação do relacionamento de causa e efeito entre as variáveis. Além disso, o desdobramento de correlações é dependente do conjunto de caracteres estudados, que normalmente é estabelecido pelo conhecimento prévio do pesquisador, e de sua importância. A técnica de correlação canônica é apropriada para estimar as relações entre dois grupos de caracteres agronômicos. Além disso, segundo Cruz; Regazzi (1994), a grande vantagem dessa técnica é a possibilidade em auxiliar o melhorista no estudo que envolva mais de uma variável dependente. 
No contexto apresentado, o presente trabalho teve como objetivo estimar a variabilidade genética e a correlação de características vinculadas ao potencial ornamental em acessos de Capsicum spp. através de descritores morfoagronômicos.

\section{MATERIAL E MÉTODOS}

O trabalho foi realizado na Universidade do Estado de Mato Grosso (UNEMAT), localizado na latitude $16^{\circ} 07^{\prime}$ 78.78" S e $57^{\circ} 65^{\prime} 30.31$ ” N, no Campus Universitário de Cáceres.

Foram utilizados 55 acessos de Capsicum spp. existentes na coleção de germoplasma da UNEMAT. Onde cada um dos 55 acessos foi semeado em bandejas de poliestireno com 128 células contendo substrato comercial Plantimax ${ }^{\circledR}$ e mantidas em casa de vegetação para germinação. Após um período de 46 dias, quando as mudas tinham de quatro a seis folhas definitivas, por volta de $10 \mathrm{~cm}$ de altura, as plântulas foram transferidas para o campo.

O Delineamento experimental utilizado foi o em blocos casualizado (DBC), sendo três blocos, com três plantas em cada parcela, sendo avaliadas as três plantas de cada parcela.

Os tratos culturais requeridos pela cultura durante todo seu ciclo foram realizados conforme recomendado por Filgueira (2005). A caracterização morfoagronômica dos acessos foi realizada considerando diferentes partes da planta, onde iniciou-se as coletas de dados quando a parcela a ser caracterizada possuía $50 \%$ ou mais de plantas com frutos. Os descritores utilizados para o gênero Capsicum foram os propostos pelo IPGRI (1995) e o recomendado por Neitzke et al., (2010) de modo a tornar mais expedita à obtenção de alguns dados. Foram avaliadas 11 variáveis quantitativas.

Os 11 descritores quantitativos utilizados para quantificar a variabilidade genética dos acessos foram analisados com base nas médias dos valores observados em cada acesso: 1) Altura de Planta - ALTP (cm), sendo medida da base da planta ao ponto mais alto da copa, utilizando-se trena, quando $50 \%$ das plantas tinham frutos maduros. 2) Largura do dossel (cm) $\mathrm{LD} ; 3)$ Comprimento do dossel (cm) CD; 4) Área do dossel $\left(\mathrm{m}^{2}\right) \mathrm{AD}$, onde multiplicou-se a largura do dossel pelo seu comprimento.
Para as características dos frutos foram avaliados: 5) Comprimento do fruto (cm) CF; 6) Diâmetro do fruto - DF; 7) Peso do fruto (massa fresca dos frutos) $\mathrm{PF}(\mathrm{g})$; 8) Comprimento do pedúnculo do fruto $(\mathrm{CPF})$. Para as análises de $\mathrm{CF}, \mathrm{PF}, \mathrm{DF}$ e CPF foram utilizadas as médias de 30 frutos maduros selecionados ao acaso. $\mathrm{O}$ CF e o $\mathrm{CPF}$ foram medidos utilizando uma régua milimétrica. $\mathrm{DF}$ foi medido com paquímetro digital e expresso em milímetros (mm). O MFF é igual à massa dos frutos obtido em gramas $(\mathrm{g})$ através de balança analítica.

Para as características das folhas foram avaliados: 9) Comprimento da folha (CF); 10) Largura da folha (LF); e 11) Comprimento do pecíolo (CP). Sendo que estas características foram mensuradas utilizando uma régua milimétrica, e expressas em centímetros.

Os dados foram analisados com base na Análise de Variância, Análise de Trilha e Variáveis Canônicas. Os cálculos dos efeitos diretos e indiretos das variáveis explicativas da análise de trilha foram feitos conforme Li (1975) e Cruz et al. (2004). As estimativas das correlações canônicas do grupo formado pelas características avaliadas foram obtidas a partir da matriz de correlação genética conforme Cruz et al. (2004).

Os procedimentos estatísticos foram realizados empregando o recurso computacional GENES (CRUZ, 2006).

\section{RESULTADOS}

Na Tabela 1, apresentam-se os resultados das análises de variância, a média geral e os coeficientes de variação relativos às 11 variáveis estudadas. Observando as médias, verificou-se variação genética entre os acessos de pimenta (teste-F, $\mathrm{P}<0,01)$, para todas as características estudadas, evidenciando a presença de variabilidade genética na população, o que é bastante favorável ao melhoramento na medida em que a heterogeneidade genética possibilita a obtenção de ganhos por meio de seleção. Esta variabilidade genética possibilita ainda o aprofundamento e continuidade de estudos biométricos, como a análise de trilha, correlações canônicas, como o proposto para o presente trabalho.

Tabela 1. Resumo da análise de variância em blocos ao acaso das 11 características avaliadas em acessos Capsicum ssp. Cáceres - MT. Table 1. Summary of the variance analysis in randomized blocks of the 11 characteristics evaluated in Capsicum ssp. Caceres - MT.

\begin{tabular}{|c|c|c|c|c|c|c|c|c|c|c|c|c|}
\hline \multirow[b]{2}{*}{ FV } & \multicolumn{12}{|c|}{ Quadrados Médios } \\
\hline & GL & DF & CFT & CPD & $\mathrm{PF}$ & $\mathrm{CPF}$ & LF & $\mathrm{CF}$ & ALTP & $\mathrm{CD}$ & LD & $\mathrm{AD}$ \\
\hline Blocos & 2 & $0,46^{\mathrm{ns}}$ & $0,06^{\mathrm{ns}}$ & $0,13^{\mathrm{ns}}$ & $0,03^{\mathrm{ns}}$ & $0,06^{\mathrm{ns}}$ & $0,004^{\mathrm{ns}}$ & $0,001^{\mathrm{ns}}$ & $17,49^{\mathrm{ns}}$ & $98,75^{\text {ns }}$ & $10,10^{\mathrm{ns}}$ & $20^{\mathrm{ns}}$ \\
\hline Acessos & 54 & $96,8 * *$ & $241,6 * *$ & $1,25 * *$ & $18,5^{* *}$ & $1,91 * *$ & $0,9 * *$ & $3,48 * *$ & $381,09 * *$ & $431,31 * *$ & $382,13 * *$ & $0,04 * *$ \\
\hline Resíduo & 108 & 1,31 & 0,27 & 0,06 & 0,06 & 0,04 & 0,04 & 0,08 & 22,24 & 31,65 & 41,57 & 0,00 \\
\hline Média & & 13,81 & 4,60 & 2,47 & 2,69 & 1,90 & 3,04 & 5,48 & 44,77 & 59,84 & 62,25 & 0,38 \\
\hline $\mathrm{CV}(\%)$ & & 8,31 & 11,48 & 10,48 & 9,20 & 11,31 & 7,25 & 5,32 & 10,54 & 9,40 & 10,36 & 14,45 \\
\hline
\end{tabular}

** significativos a 1\% de probabilidade pelo teste F; ns: não-significativo pelo teste F. Diâmetro do Fruto(DF); Comprimento do Fruto (CFT); Comprimento do Pedúnculo (CPD); Peso do Fruto (PF); Comprimento do Pecíolo da Folha (CPF); Largura da Folha (LF); Comprimento da Folha (CF); Altura da Planta (ALTP); Comprimento do Dossel (CD); Largura do Dossel (LD); Área do Dossel (AD).

** Significant at $1 \%$ probability by F test; ns: non- significant by test F. Fruit diameter (DF); Fruit length (CFT); Length of peduncle (CPD); Fruit weight (PF); Petiole Sheet Length (CPF); Sheet width (LF); Leaf length (CF); Plant height (ALTP); Length Canopy (CD); Width of the canopy (LD); Canopy area (AD).

Os coeficientes de variação encontrados para as 11 variáveis analisadas apresentaram valores de diferentes magnitudes, variando entre 5,32 a 14,45. Estes valores são considerados baixos a medianos, contudo, com valores considerados aceitáveis. Para o carácter área do dossel (AD) foi verificado o maior coeficiente de variação, $14,45 \%$, sendo assim, essa característica pode ser considerada como a de maior sensibilidade à variação ambiental e, portanto, mais sujeita a erros experimentais. A característica comprimento da folha (CF) obteve o menor coeficiente de variação, com $5,32 \%$, podendo-se considerar esta característica a menos influenciada pelo ambiente. Nas demais características estudadas podem-se considerar que os coeficientes de variação calculados foram de médios a baixos quanto à interferência ambiental. 
Na análise das estimativas dos coeficientes de correlação fenotípica, segundo os efeitos diretos das variáveis estudadas sobre a variável altura da planta (Tabela 2 e 3), verificou-se correlações negativas com as variáveis diâmetro do fruto, comprimento do fruto, comprimento do pedúnculo, peso do fruto e pecíolo da folha. Observa-se, também, correlações positivas com as variáveis, largura da folha, comprimento da folha, comprimento do dossel, largura do dossel, e área do dossel. Todas estas correlações, as positivas e as negativas, apresentaram valores inferiores ao efeito residual $\left(\mathrm{R}^{2}=0,7472\right)$.

Tabela 2. Estimativas dos efeitos diretos e indiretos entre a variáve Altura da Planta (cm, g por parcela) e as variáveis: Diâmetro do Fruto, Comprimento do Fruto, Comprimento do Pedúnculo, peso do fruto. Cáceres-MT

Table 2. Estimates of the direct and indirect effects between the variable plant height $(\mathrm{cm}, \mathrm{g}$ per portion) and the variables: fruit diameter, fruit length, Comp. the peduncle, fruit fresh mass. CáceresMT

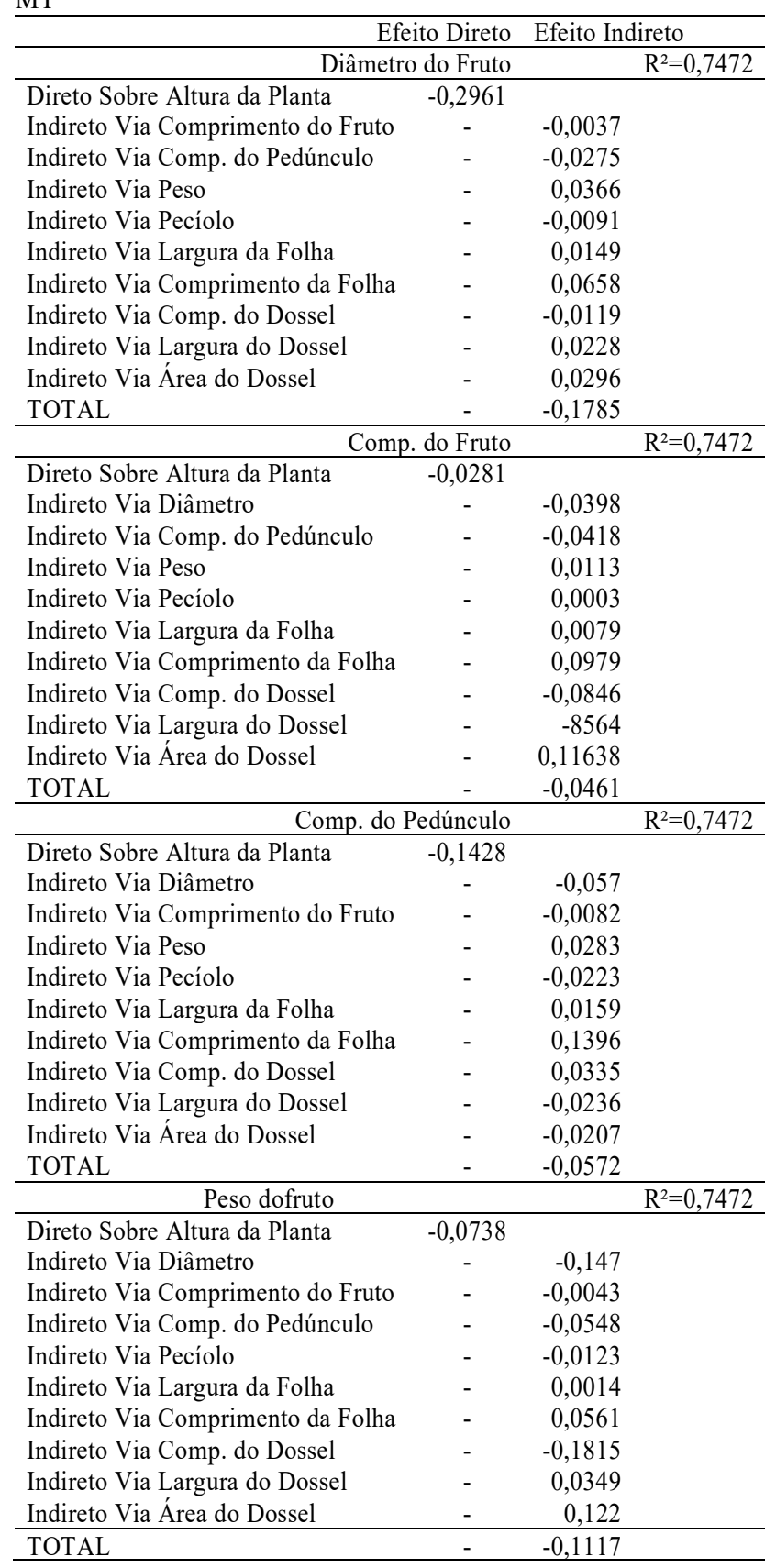

Tabela 3. Estimativas dos efeitos diretos e indiretos entre a variável Altura da Planta (cm, g por parcela) e as variáveis: Peso, Pecíolo, Largura da Folha, Comprimento da Folha, Comprimento do Dossel, Largura do Dossel, Área do Dossel. Cáceres-MT

Table 3. Estimates of the direct and indirect effects between the variable plant height $(\mathrm{cm}, \mathrm{g}$ per portion) and the variables: weight, petiole, leaf width, leaf length, Comp. Canopy, Width Canopy, Canopy area. Cáceres-MT

\begin{tabular}{lcc}
\hline & Efeito Direto & Efeito Indireto \\
\hline & Pecíolo & $\mathrm{R}^{2}=0,7472$ \\
\hline Direto Sobre Altura da Planta & $-0,0469$ & - \\
Indireto Via Diâmetro & - & - \\
Indireto Via Comprimento do Fruto & - & 0,0002 \\
Indireto Via Comp. do Pedúnculo & - & - \\
Indireto Via Peso & - & 0,0194 \\
Indireto Via Largura da Folha & - & 0,0245 \\
Indireto Via Comprimento da Folha & - & 0,1039 \\
Indireto Via Comp. do Dossel & - & 0,007 \\
Indireto Via Largura do Dossel & - & - \\
Indireto Via Área do Dossel & - & - \\
TOTAL & - & - \\
\hline
\end{tabular}

\begin{tabular}{lcl}
\hline & - & - \\
\hline Lireto Sobre Altura da Planta & 0,0941 &
\end{tabular}

Indireto Via Diâmetro

Indireto Via Comprimento do Fruto

Indireto Via Comp. do Pedúnculo

Indireto Via Peso

Indireto Via Pecíolo

Indireto Via Comprimento da Folha $\quad$ - $\quad 0,3241$

Indireto Via Comp. do Dossel _ - 0,2271

Indireto Via Largura do Dossel — $\quad$ - $\quad 0,1308$

Indireto Via Área do Dossel

TOTAL

- $\quad 0,4391$

\begin{tabular}{lcl} 
& Comp. da Folha & $\mathrm{R}^{2}=0,7472$ \\
\hline Direto Sobre Altura da Planta & 0,3945 & \\
Indireto Via Diâmetro & - & - \\
Indireto Via Comprimento do Fruto & - & -
\end{tabular}

Indireto Via Comp. do Pedúnculo

Indireto Via Peso

Indireto Via Pecíolo

Indireto Via Largura da Folha

Indireto Via Comp. do Dossel

Indireto Via Largura do Dossel

Indireto Via Área do Dossel TOTAL

\begin{tabular}{|c|c|c|c|}
\hline TOTAL & \multirow{2}{*}{\multicolumn{2}{|c|}{$\frac{-}{\text { Comp. do Dossel }}$}} & \\
\hline Comp & & & $\mathrm{R}^{2}=0,7472$ \\
\hline Direto Sobre Altura da Planta & 0,708 & & \\
\hline Indireto Via Diâmetro & - & 0,005 & \\
\hline Indireto Via Comprimento do Fruto & - & 0,0033 & \\
\hline Indireto Via Comp. do Pedúnculo & - & - & \\
\hline Indireto Via Peso & - & - & \\
\hline Indireto Via Pecíolo & - & - & \\
\hline Indireto Via Largura da Folha & - & 0,0302 & \\
\hline Indireto Via Comprimento da Folha & - & 0,082 & \\
\hline Indireto Via Largura do Dossel & - & 0,3781 & \\
\hline Indireto Via Área do Dossel & - & - & \\
\hline \multirow{2}{*}{ TOTAL } & - & 0,4102 & \\
\hline & Larg. do Dossel & & $\mathrm{R}^{2}=0,7472$ \\
\hline Direto Sobre Altura da Planta & 0,6065 & & \\
\hline Indireto Via Diâmetro & - & - & \\
\hline Indireto Via Comprimento do Fruto & - & 0,0039 & \\
\hline Indireto Via Comp. do Pedúnculo & - & 0,0055 & \\
\hline Indireto Via Peso & - & 0,0042 & \\
\hline Indireto Via Pecíolo & - & 0,0058 & \\
\hline Indireto Via Largura da Folha & - & 0,0203 & \\
\hline Indireto Via Comprimento da Folha & - & 0,0866 & \\
\hline Indireto Via Comp. do Dossel & - & 0,4413 & \\
\hline Indireto Via Área do Dossel & - & - & \\
\hline TOTAL & - & 0,4348 & \\
\hline Área & o Dossel & & $\mathrm{R}^{2}=0,7472$ \\
\hline
\end{tabular}


Direto Sobre Altura da Planta

Indireto Via Diâmetro

Indireto Via Comprimento do Fruto

Indireto Via Comp. do Pedúnculo

Indireto Via Peso

Indireto Via Pecíolo

Indireto Via Largura da Folha

Indireto Via Comprimento da Folha

Indireto Via Comp. do Dossel

Indireto Via Largura do Dossel

TOTAL

0,8501

0,0103

0,0038

-

0,0279

0,6415

0,5198

0,4438

Nas estimativas dos coeficientes de correlação fenotípica, segundo os efeitos indiretos das correlações negativas, entre a variável altura da planta e as demais variáveis, observa-se que a correlação com o diâmetro do fruto foi determinada pelo efeito indireto do comprimento da folha $(0,0658)$, então, a seleção baseada na altura da planta para obter ganho no diâmetro do fruto e influenciará o comprimento da folha. A correlação com a variável comprimento do fruto foi determinada pelo efeito indireto da área do dossel $(0,1163)$. Assim, para se fazer uma seleção baseada na altura da planta para obter ganho no comprimento do fruto deve-se levar em consideração o efeito indireto da área do dossel. Em relação a variável comprimento do pedúnculo, a correlação foi determinada pelo efeito indireto do comprimento da folha (0,1396), o qual será influenciada em uma possível seleção para se obter ganho no comprimento do pedúnculo. A correlação fenotípica com o peso do fruto foi determinada pelo efeito indireto da área do dossel $(0,1220)$. Uma possível seleção para obter ganho no peso do fruto influenciará, indiretamente, a área do dossel. E a correlação com o pecíolo da folha foi determinada, pelo efeito indireto, do comprimento da folha. Onde a mesma deverá ser considerada em caso de seleção para se obter ganho no pecíolo da folha.

As estimativas dos coeficientes de correlação fenotípica, segundo os efeitos diretos e indiretos das correlações positivas, entre a variável altura da planta e as demais variáveis, deramse principalmente ao efeito direto dessas variáveis, o que mostra que elas são importantes na seleção direta da variável altura da planta. Observou-se também, o efeito indireto da variável largura da folha $(0,4391)$ na seleção da altura da planta para obter ganho na largura da folha. $\mathrm{O}$ efeito indireto do comprimento do dossel $(0,1473)$, para se obter ganho no comprimento da folha. O efeito indireto da largura do dossel $(0,3781)$ para se obter ganho no comprimento do dossel. E o efeito indireto do comprimento do dossel, de 0,4413 e 0,6415, respectivamente, para se obter ganho de seleção na largura do dossel e área do dossel.

As cargas canônicas para os pares canônicos entre as variáveis do Grupo I e as do Grupo II são apresentadas na Tabela 4, onde segundo Hair Junior et al. (2005), as cargas canônicas (ou correlações estruturais canônicas) medem a correlação linear simples entre uma variável original observada no conjunto dependente ou independente e a variável estatística canônica do seu respectivo conjunto. Quanto maior a carga, mais importante é a variável para derivar a variável estatística canônica.

Analisando as cargas canônicas, do primeiro par canônico, para a variável canônica relativa às características área do dossel, largura do dossel, comprimento do dossel e altura da planta, grupo i, observa-se que as mesmas apresentaram (em módulo) valores elevados: 0,$42 ; 0,28 ; 0,29 ; 0,78$, respectivamente. Já para o outro grupo de características, apenas o comprimento do fruto $(0,027)$ e comprimento do pedúnculo $(0,002)$ apresentaram baixa carga canônica, sendo que as demais cargas canônicas apresentaram valores elevados. Pode-se observar também que as variáveis, largura e comprimento de folha são determinantes para a altura da planta.

Tabela 3. Cargas canônicas para os pares canônicos entre o Grupo I e Grupo II para 11 variáveis de pimenteiras, Cáceres - MT

Table 3. Canonical loads for canonical pairs between Group I and Group II for 11 variables of peppercorns, Cáceres - MT

\begin{tabular}{|c|c|c|c|c|c|}
\hline \multirow{2}{*}{ Grupo } & \multirow{2}{*}{ Variáveis } & \multicolumn{4}{|c|}{ Cargas Canônicas } \\
\hline & & $1^{\circ}$ & $2^{\circ}$ & $3^{\circ}$ & $4^{\circ}$ \\
\hline \multirow{4}{*}{ I } & Área do Dossel & 0,427 & $-0,342$ & $-0,337$ & 0,765 \\
\hline & Largura do Dossel & 0,286 & 0,105 & $-0,591$ & 0,746 \\
\hline & $\begin{array}{l}\text { Comprimento Do } \\
\text { Dossel }\end{array}$ & 0,294 & $-0,700$ & $-0,328$ & 0,561 \\
\hline & Altura & 0,781 & $-0,115$ & $-0,589$ & $-0,167$ \\
\hline \multirow{7}{*}{ II } & Diâmetro Do Fruto & $-0,480$ & 0,023 & $-0,209$ & 0,397 \\
\hline & Comp. Do Fruto & $-0,027$ & 0,051 & 0,165 & $-0,631$ \\
\hline & Comp. do Pedúnculo & $-0,002$ & $-0,153$ & 0,195 & 0,208 \\
\hline & Peso Do Fruto & $-0,242$ & 0,656 & $-0,158$ & 0,099 \\
\hline & Pecíolo Da Folha & 0,167 & $-0,143$ & 0,580 & 0,218 \\
\hline & Largura da Folha & 0,584 & $-0,371$ & $-0,456$ & $-0,018$ \\
\hline & $\begin{array}{l}\text { Comprimento da } \\
\text { Folha }\end{array}$ & 0,735 & $-0,051$ & $-0,236$ & 0,164 \\
\hline
\end{tabular}

Os resultados encontrados de cargas canônicas, no primeiro par canônico, evidenciam que a área do dossel está correlacionada positivamente com a largura do dossel, o comprimento do dossel e a altura da planta, sendo que a largura e o comprimento do dossel apresentaram as menores correlações, 0,28 e 0,29 respectivamente. No segundo grupo de variáveis, pode-se observar que somente o pecíolo da folha, a largura da folha e o comprimento da folha estão correlacionados positivamente. Por outro lado, o diâmetro e o comprimento do fruto, o comprimento do pedúnculo, e o peso do fruto estão negativamente correlacionados. De modo que se pode inferir que quando a área e a largura do dossel, a largura e o comprimento da folha, o comprimento do dossel, a altura e o pecíolo da folha apresentarem valores mais elevados, menores serão o diâmetro do fruto, o comprimento do pedúnculo e o peso do fruto.

Conforme os resultados obtidos, das cargas canônicas, do segundo par canônico para as variáveis do primeiro grupo, pode-se observar que as variáveis, área, largura, comprimento do dossel e altura da planta apresentaram (em módulo) valores elevados: 0,$34 ; 0,10 ; 0,70$; e 0,11 respectivamente. Para o grupo II, as características diâmetro do fruto $(0,023)$, comprimento do fruto $(0,051)$ e comprimento da folha $(0,051)$ apresentaram baixa carga canônica. Ainda no segundo par canônico, observa-se que não existe, para o primeiro grupo de variáveis, correlação positiva. Onde as variáveis, área e comprimento do dossel e a altura da planta estão correlacionadas negativamente. De modo que se pode afirmar que quanto menor for a área do dossel menor será o comprimento do dossel e a altura da planta. No segundo grupo de variáveis, pode-se observar que o diâmetro, o comprimento e o peso do fruto estão positivamente correlacionados, no entanto, somente o peso do fruto apresentou carga canônica elevada, 0,65 . Já as características comprimento do pedúnculo, pecíolo, largura e comprimento da folha estão negativamente correlacionados. Observa-se ainda que folhas menores e peso de frutos maiores, tendem a proporcionar menor comprimento do dossel. 
No terceiro par canônico, nas cargas canônicas do primeiro grupo, pode-se observar que todas as variáveis apresentaram valores elevados (em módulo), sendo a menor carga canônica da variável comprimento do dossel $(0,32)$, e a maior carga canônica da variável largura do dossel $(0,59)$. Já no segundo grupo as cargas canônicas variaram entre 0,15 , na variável peso do fruto, a 0,58 na variável pecíolo da folha. Pode-se observar ainda, que todas as cargas foram negativas no primeiro grupo. Para o segundo grupo de cargas canônicas, verifica-se que o comprimento do fruto $(0,16)$, comprimento do pedúnculo $(0,19)$, e o pecíolo da folha $(0,58)$, estão correlacionados positivamente.

As demais variáveis estão correlacionadas negativamente, sendo diâmetro do fruto $(-0,20)$, peso do fruto $(-0,15)$, largura da folha $(-0,45)$ e comprimento da folha $(-0,23)$. Observa-se ainda que largura folhas menores e pecíolo das folhas maiores, tendem a proporcionar menor largura do dossel.

No quarto e último par canônico, nas variáveis do primeiro grupo, pode-se observar que todas as variáveis apresentaram cargas canônicas elevadas (em módulo), sendo a menor carga da variável altura da planta com 0,32 e as maiores cargas canônicas das variáveis, área do dossel com 0,76 e largura do dossel com 0,74.

Já no segundo grupo de cargas canônicas, os maiores valores de carga canônica foram da variável comprimento do fruto com 0,63 . Os menores valores foram das variáveis, peso de fruto $(0,09)$ e largura da folha $(0,01)$. Observa-se também que a variável altura da planta está correlacionada com as demais variáveis negativamente $(-0,16)$. As variáveis, área, largura e comprimento do dossel estão correlacionadas positivamente, com 0,$76 ; 0,74 ; 0,56$ de carga canônica respectivamente. No segundo grupo de cargas canônicas, observa-se que as variáveis, comprimento e a largura da folha, estão correlacionados negativamente, com $-0,63$ e $-0,01$ respectivamente de cargas canônicas, sendo que as demais variáveis apresentaram correlações positivas. Observa-se ainda que menores comprimentos do fruto e maiores diâmetros dos frutos tendem a proporcionar menores comprimentos de dossel.

A Tabela 5 apresenta os coeficientes da matriz estrutural ou matriz dos fatores canônicos, ou seja, a matriz de correlação entre as variáveis originais e as canônicas. A interpretação por meio das correlações entre as variáveis originais e as canônicas fornece, em geral, o caminho mais adequado para a seleção. Verificou-se que as três primeiras correlações canônicas foram significativas. Isso indica que os dois grupos de características não podem ser considerados independentes. E as associações intergrupos foram estabelecidas, principalmente, pelas influências de:

a) O primeiro par de correlações canônicas, com correlação de 0,61 , associa plantas com o dossel curto e estreito, e plantas altas com folhas compridas e frutos curtos. Esta associação para fins ornamentais seria vantajosa se não fosse pela associação com plantas altas, sendo que para ornamentação o ideal são plantas de porte baixo.

b) O segundo par de correlações canônicas, com correlação de 0,54 , associa plantas com dossel maior quanto se refere à área e largura do dossel, mas com comprimento do dossel menor, associado a folhas estreitas e compridas, e fruto pesado. Esta associação para plantas ornamentais não é vantajosa, uma vez que para esta finalidade preferem-se plantas com dossel relativamente compacto e fruto leve para que o mesmo não fique pendente na planta e sim com o ápice do fruto apontando para cima.

c) O terceiro par de correlações canônicas, com correlação de 0,51, associa plantas com área do dossel compacto-densa, com comprimento e largura de dossel menor e de pequeno porte, associado com folhagens estreitas e de pecíolo grande.

Tabela 4. Coeficientes de correlações canônicas e pares canônicos estimados entre variáveis do Grupo I e variáveis do Grupo II de Pimenteira. Cáceres-MT

Table 4. Coefficients of canonical correlations and canonical pairs estimated between variables of Group I and variables of the pepper Group II. Cáceres-MT

\begin{tabular}{clcccc}
\hline \multirow{2}{*}{ Grupo } & \multicolumn{1}{c}{ Variáveis } & \multicolumn{4}{c}{ Par Canônico } \\
\cline { 3 - 6 } & & $1^{\circ}$ & $2^{\circ}$ & $3^{\circ}$ & $4^{\circ}$ \\
\hline \multirow{2}{*}{ I } & Área do Dossel & 3,146 & 0,850 & 3,574 & 1,505 \\
& Largura do Dossel & $-1,588$ & 0,471 & $-2,230$ & 0,114 \\
& Comprimento Do & $-1,921$ & $-1,777$ & $-2,022$ & $-0,614$ \\
& Dossel & & & & \\
& Altura & 0,863 & 0,031 & $-0,376$ & $-0,633$ \\
\hline \multirow{2}{*}{ Diâmetro Do Fruto } & $-0,581$ & $-0,320$ & $-0,123$ & 0,580 \\
& Comprimento do Fruto & $-0,111$ & $-0,012$ & 0,270 & $-0,903$ \\
& Comprimento Do & $-0,287$ & $-0,571$ & $-0,121$ & 0,279 \\
& Pedúnculo & & & & \\
& Peso Do Fruto & $-0,027$ & 0,943 & $-0,372$ & $-0,278$ \\
& Pecíolo Da Folha & 0,191 & $-0,039$ & 0,918 & 0,015 \\
& Largura da Folha & $-0,205$ & $-0,909$ & $-0,986$ & $-0,827$ \\
& Comprimento da Folha & 1,084 & 0,830 & 0,380 & 0,908 \\
\hline Correlação & 0,606 & 0,544 & 0,512 & 0,189 \\
\hline
\end{tabular}

\section{DISCUSSÃO}

Em trabalho realizado por Negreiros; Miqueloni (2013), com o objetivo de avaliar a divergência genética entre populações de pimenta longa (Piper hispidinervum), concluíram que, assim como no presente trabalho, as análises de variância mostraram que todas as características expressaram diferenças significativas, portanto, os resultados indicam que os acessos são diferentes, nos caracteres estudados, com possibilidades de ganhos por seleção. E segundo Costa et al. (2009) a identificação de divergência entre os acessos, é um indicativo de que os mesmos podem apresentar diferentes características agronômicas e por isso, poderão ser explorados em programas de melhoramento.

A análise de trilha consiste na quantificação dos efeitos diretos e indiretos das variáveis explicativas sobre uma variável básica (CRUZ; REGAZZI, 1994). Segundo Cruz et al. (2004), caracteres com correlação favorável com a variável básica, mas com efeito direto em sentido contrário, valor negativo, indicam a ausência de causa e efeito, ou seja, aquela variável auxiliar não é o principal determinante das alterações na variável básica, existindo outras variáveis que poderão proporcionar maior impacto em termos de ganho de seleção. Portanto, as correlações fenotípicas detectadas entre a variável altura de planta e as variáveis, diâmetro do fruto, comprimento de fruto, comprimento do pedúnculo, peso do fruto, pecíolo da folha não apresentou uma relação causa-efeito e foi determinada, indiretamente, por outra variável.

Em estudos realizados por Melo et al. (2014), avaliando o potencial ornamental de acessos de pimenta, selecionaram sete acessos, onde a altura da planta e sua relação com as demais variáveis, foi uma importante variável para a seleção desses acessos. 
Nos coeficientes de correlações canônicas e pares canônicos estimados, no primeiro e o segundo par canônico, as associações observadas são desvantajosas para a ornamentação de pimenteiras. De acordo com Pinto et al. (2010), a ornamentação de pimenteiras é importante uma relação harmônica entre as características do fruto e o porte da planta para a seleção de acessos, sendo preferenciais os acessos que produzam frutos menores, pois frutos grandes, além de tenderem a posição pendente, o que dificulta sua visualização por se esconderem atrás das folhas, podem levar ao rompimento nos galhos em função do peso.

As associações do terceiro par de correlações canônicas são vantajosas para ornamentação, segundo Carvalho et al. (2006), o gênero Capsicum é utilizado como ornamental quando possuem folhagem variegada, porte baixo, frutos com coloração variada em seus diferentes estádios de maturação e que contrastam com a folhagem. Tais caracteres conferem valor estético às pimentas com uma beleza singular atraindo até mesmo aqueles que não gostam de consumir o fruto, mas que passam a apreciá-las também para ornamentação.

\section{CONCLUSÕES}

Ficou evidenciada a presença de variabilidade genética morfológica na população, o que é bastante favorável ao melhoramento na medida em que a heterogeneidade genética possibilita a obtenção de ganhos por meio de seleção.

Os resultados da análise de trilha evidenciam que a seleção baseada na altura da planta em relação direta á outra característica, só é uma boa estratégia se levar em consideração os efeitos indiretos das outras características avaliadas.

Os resultados encontrados de cargas canônicas evidenciam que a seleção baseada no terceiro e quarto par de cargas canônicas resultariam em ganhos para a ornamentação.

As análises de correlação canônica permitem observar que os grupos considerados não são independentes e que as associações intergrupos para fins de ornamentação são estabelecidas, principalmente, pela influência do terceiro par de correlações canônicas que associa plantas com área do dossel compacto, com comprimento e largura de dossel menor e de porte baixo, associado folhagens estreitas e de pecíolo grande.

\section{REFERÊNCIAS}

BABA, V. Y.; ROCHA, K. R.; GOMES, G. P.; RUAS, C. F.; RUAS, P. M.; RODRIGUES, R.; GONÇALVES, L. S. A. Genetic diversity of Capsicum chinense accessions based on fruit morphological characterization and AFLP markers. Genetic Resources and Crop Evolution, Dordrecht, v. 63, n. 8, p. 1371-1381, 2016. DOI: https://dx.doi.org/10.1007/s10722-015-0325-4

Referência excluída.

BOTELHO, F. B. S.; RODRIGUES, C. S.; BRUZI, A. T. Ornamental Plant Breeding. Ornamental Horticulture, Campinas, v. 21, n. 1, p. 9-16, 2015 DOI: https://doi.org/10.14295/rbho.v21i1.770

CARVALHO, S. I. C.; BIANCHETTI, L. B.; RIBEIRO, C. S. C.; LOPES, C. A. Pimentas do gênero Capsicum no Brasil. Brasília: Embrapa Hortaliças, 2006. 27 p. (Documentos, 94).

COSTA, F. R.; PEREIRA, T. N. S.; SUDRÉ, C. P.; RODRIGUES, R. Marcadores RAPD e caracteres morfoagronômicos na determinação da diversidade genética entre acessos de pimentas e pimentões. Ciência Rural, Santa Maria, v. 39, n.3, p. 696-704, 2009. DOI: http://dx.doi.org/10.1590/S0103-84782008005000099

CRUZ, C. D.; REGAZZI, A. J. Modelos biométricos aplicados ao melhoramento genético. Viçosa: UFV, Imp. Univ., 1994. 390 p.

CRUZ, C. D.; REGAZZI, A. J.; CARNEIRO, P. C. S. Modelos biométricos aplicados ao melhoramento genético. 3. ed. Viçosa, MG: UFV, 2004. 480 p.

CRUZ, C. D.; REGAZZI, A. J.; CARNEIRO, P. C. S. Modelos biométricos aplicados ao melhoramento genético. 4. ed. Viçosa: UFV, 2012. 1 v. 514 p.

CRUZ, C. D. Programa Genes: Biometria. Editora UFV. Viçosa, 382 p. 2006.

FILGUEIRA, F. A. R. Novo Manual de Olericultura. Viçosa: UFV, 2005, 413 p.

HAIR JUNIOR, F.; ANDERSON, R. E.; TATHAM, R. L.; BLACK, W. C. Análise multivariada de dados. Porto Alegre: Bookman, 2005. 593 p.

IPGRI. Descriptores para Capsicum (Capsicum spp). Roma: IPGRI, 1995. $51 \mathrm{p}$.

LI, C. C. Path analysis a primer. Pacific Grove. The Boxwood Press. 1975. 346 p.

MELO, L. F.; GOMES, R. L. F.; SILVA, V. B.; MONTEIRO, E. R.; LOPES, Â. C. A.; PERON, A. P. Potencial ornamental de acessos de pimenta. Ciência Rural, Santa Maria, v. 44, n. 11, p. 2010-2015, 2014. DOI: http://dx.doi.org/10.1590/0103-8478cr20131306

NEGREIROS J. R. S.; MIQUELONI, D. P. Divergência genética de populações de Piper hispidinervum C. DC. com base em caracteres morfoagronômicos. Pesquisa Agropecuária Tropical, Goiânia, v. 43, n. 2, p. 209-217, 2013. DOI: http://dx.doi.org/10.1590/S198340632013000200007

NEITZKE, R. S.; BARBIERI, R. L.; RODRIGUES, W. F.; CORREA, I. V.; CARVALHO, F. I. F. Dissimilaridade genética entre acessos de pimenta com potencial ornamental. Horticultura Brasileira, Brasília, v. 28, n.1, p. 47-53, 2010. DOI: http://dx.doi.org/10.1590/S010205362010000100009

OLIVEIRA. M. K. T.; OLIVEIRA. F. A.; MEDEIROS. J. F.; LIMA. C. J. G.; GALVÃO. D. C. Avaliação de substratos orgânicos na produção de mudas de berinjela e pimenta. Revista Verde, Pombal, v. 1, n. 2, p. 24-32, 2006. DOI: https://dx.doi.org/10.18378/rvads.v1i2.12

PINTO, C. M. F.; BARBOSA, J. M.; MESQUITA, D. Z.; OLIVEIRA, F.; MAPELI, A. M.; SEGATTO, F. B.; BARBOSA, J. G. Produção e qualidade de pimentas ornamentais comestíveis cultivadas em recipientes de diferentes volumes. Revista Brasileira de Horticultura Ornamental, Campinas v. 16, n. 1, p. 113-122, 2010. DOI: https://dx.doi.org/10.14295/rbho.v16i1.519

SILVA, F. C.; RIBEIRO, W.; COSTA, L. C.; PINTO, C. M. F.; DEDO, F. L. Evaluation of substrates on the production of ornamental Capsicum. Acta Horticulturae, The Hague, v. 1060, p. 115-120. 2015. DOI: https://dx.doi.org/10.17660/ActaHortic.2015.1060.15 